\title{
Evaluation of femtosecond laser in flap and cap creation in corneal refractive surgery for myopia: a 3-year follow-up
}

This article was published in the following Dove Press journal:

Clinical Ophthalmology

\author{
Mohamed Nagy \\ Elmohamady \\ Walid Abdelghaffar \\ Ahmed Daifalla \\ Tamer Salem \\ Ophthalmology Department, Benha \\ University, Banha, Egypt
}

\begin{abstract}
Purpose: To evaluate femtosecond laser in flap and cap creation, detect some corneal biomechanical changes, and evaluate dry eye after laser in situ keratomileusis (LASIK), FemtoLASIK, and small incision lenticule extraction (SMILE) with 3-year follow-up.

Patients and methods: Preoperative evaluation taken: full ophthalmic examination, Pentacam, ocular response analyzer, ocular surface disease index (OSDI), and tear breakup time (TBUT). LASIK flap was created using Moria microkeratome in 30 eyes (LASIK group) and using VisuMax femtosecond laser in 38 eyes (FS-LASIK group) and SMILE was done by VisuMax in 35 eyes (SMILE group). Postoperative evaluation: anterior segment optical coherence tomography to measure flap and cap thickness, ocular response analyzer to measure corneal hysteresis $(\mathrm{CH})$ and corneal resistance factor (CRF), OSDI, and TBUT at 1, 3, 6, 12, 24, and 36 months after surgery.

Results: This study included 103 eyes of 103 patients. The mean deviation of central cap or flap thickness from intended was statistically higher in the LASIK group $(P<0.001)$. Both $\mathrm{CH}$ and CRF showed significant reduction postoperatively but were significantly higher in the SMILE group during follow up $(P<0.05)$. The mean OSDI scores were significantly elevated in all groups postoperatively $(P<0.01)$ but were significantly lower in the SMILE group 3 months postoperatively $(P<0.05)$. The mean TBUT was significantly decreased in all groups postoperatively $(P<0.01)$ but was significantly higher in the SMILE group 6 months postoperatively $(P<0.05)$.
\end{abstract}

Conclusion: Femtosecond laser is more accurate than microkeratomes. $\mathrm{CH}$ and $\mathrm{CRF}$ changes were least after SMILE. The three procedures led to significant dryness but for shorter duration with SMILE.

Keywords: LASIK, femtosecond laser, SMILE, dry eye, corneal biomechanics, myopia

\section{Introduction}

Due to its safety and accuracy, laser in situ keratomileusis (LASIK) has become the most popular procedure for the surgical management of myopia. ${ }^{1}$ During LASIK surgery, creation of a corneal flap is the first and the most critical step, as it influences the visual outcome. Flap formation has progressed from using mechanical microkeratomes to using the femtosecond laser. ${ }^{2}$ In the past decade, the femtosecond laser has been used in a wide range of procedures, allowing tailoring of the parameters of the corneal flap, such as diameter, thickness, and hinge position, which are the main benefits of using the femtosecond laser. Accordingly, it may lessen the risk of flap complications such as irregular, buttonholed or incomplete flaps. ${ }^{3,4}$ Small incision lenticule extraction (SMILE) is a procedure during which the femtosecond laser creates an intrastromal lenticule and then the surgeon extracts it through a small incision with no need for flaps. ${ }^{5}$
Correspondence: Mohamed Nagy Elmohamady

Ophthalmology Department, Benha University, Farid Nada Street,

Banha, Egypt

Tel +20 I00 I078058

Email mohamed.saad@fmed.bu.edu.eg 
Corneal biomechanical properties are crucial in refractive surgery to discover any corneal anomaly and to maintain good postoperative quality of vision. ${ }^{6}$ Some aspects of the corneal biomechanical properties are investigated using the ocular response analyzer (ORA), which measures corneal hysteresis $(\mathrm{CH})$ and corneal resistance factor (CRF). CH reflects the corneal viscoelastic properties, and CRF measures the whole corneal rigidity. ${ }^{7}$ There is an alteration in corneal biomechanics following different refractive procedures. ${ }^{8}$ Dry eye is a common complaint among patients who have undergone refractive surgeries. ${ }^{9}$ It is believed that the post-surgical development of dry eye is closely connected to the surgical cut of the corneal nerve fibers that is done during corneal refractive surgery. ${ }^{10}$

In several studies, researchers have evaluated the safety, efficiency, and precision of the femtosecond laser in flap creation $^{2}$ and compared femtosecond laser to mechanical microkeratomes. ${ }^{11}$ Also, the ReLEX or SMILE procedure has been studied for its efficacy and safety ${ }^{12}$ and compared to femtosecond laser assisted LASIK in previous studies. ${ }^{13,14}$ Corneal biomechanical changes following different corneal refractive procedures have also been studied. ${ }^{15}$ The purpose of this work was to evaluate femtosecond laser in flap and cap creation, detect some corneal biomechanical changes, and evaluate dry eye after LASIK, FemtoLASIK, and SMILE with 3-year follow-up.

\section{Patients and methods}

In this study, we included 103 eyes of 103 patients ( 40 males, 63 females) who were above 18 years of age, had myopia from -3.00 to -10.00 , astigmatism less than $4 \mathrm{D}$, and had refractive stability for at least 1 year. While patients with complicated surgeries, past history of another eye surgery, eye trauma, ocular or systemic diseases, were excluded. This study was approved by the research ethics committee at Benha University. Written informed consent was obtained from all subjects before surgery, as per the Declaration of Helsinki.

We divided the patients into three groups:

- LASIK group: the LASIK group included 30 eyes of 30 patients who underwent conventional LASIK surgery.

- FS-LASIK group: the femtosecond laser-LASIK group included 38 eyes of 38 patients who underwent LASIK surgery with the flap created by the femtosecond laser.

- SMILE group: the SMILE group included 35 eyes of 35 patients who underwent SMILE surgery.

\section{Preoperative evaluation}

All the patients had a comprehensive ophthalmic examination, cycloplegic refraction, ocular surface disease index (OSDI) questionnaire, corneal imaging using a rotating Scheimpflug camera (Pentacam, Oculus, Germany); and corneal biomechanical properties were measured using Reichert ORA.

\section{Surgical procedure}

At the beginning of the procedure, we instilled anesthetic drops in the eyes after the patients underwent sterile draping and preparation.

In the LASIK group, after selecting the suction ring according to Moria M2 nomogram which is based on the keratometric value K1, the flaps were created using Moria blades with a planned thickness of $100 \mu \mathrm{m}$. Then, the laser ablation of the stromal bed was done using the Meditec MEL90 excimer laser (Carl Zeiss Meditech, Jena, Germany).

In the FS-LASIK group, $100 \mu \mathrm{m}$ was the planned thickness of the flap created using a $500 \mathrm{kHz}$ femtosecond laser (Carl Zeiss Meditec VisuMax femtosecond laser system). Then, laser ablation using the Meditec MEL90 excimer laser (Carl Zeiss Meditech) was done.

In the SMILE group, having created the lenticule in the corneal stroma with a $500 \mathrm{kHz}$ femtosecond laser (Carl Zeiss Meditec VisuMax femtosecond laser system), we extracted the lenticule through a small incision.

\section{Postoperative care}

Tobramycin $0.3 \%$ dexamethasone $0.1 \%$ (Tobradex) and moxifloxacin $0.5 \%$ (Vigamox) eye drops were administered topically three times daily for 2 weeks and tear substitute eye drops were used three times per day for at least 3 months. A full ophthalmic examination was done in all subjects 1, 3, $6,12,24$, and 36 months postoperatively.

\section{Imaging}

At every postoperative visit, anterior segment optical coherence tomography (AS-OCT) (Topcon 3D OCT-2000; Topcon Corporation, Tokyo, Japan) was utilized to measure the central flap thickness in LASIK and FemtoLASIK groups and the central cap thickness in the SMILE group. Corneal biomechanical parameters ( $\mathrm{CH}$ and $\mathrm{CRF}$ ) were measured using Reichert ORA.

\section{OSDI}

The OSDI questionnaire was used to quantify the dry eye symptoms before surgery and 1, 3, 6, 12, 24, and 36 months 
postoperatively. In this questionnaire, patients were asked about dry eye symptoms that they had over a 1-week recall period. Each answer was scored on a 4-point scale from zero (representing no problems) to four (representing a substantial problem). Accordingly, we combined the responses to generate a composite OSDI score, higher OSDI scores indicate more severe symptoms.

\section{Tear breakup time (TBUT)}

A fluorescein impregnated strip moistened with nonpreservative saline solution was placed in the lower conjunctival fornix. Using slit-lamp biomicroscopy with a cobalt blue filter, the time elapsed before the observation of the first tear film breakup after the patient blinked was recorded as the TBUT.

\section{Statistical analysis}

We included only one eye per patient for statistical purposes. SPSS version 20.0 (IBM Corporation, Armonk, NY, USA) was used in the statistical analysis and results are stated as mean $\pm \mathrm{SD}$. To ensure the normal distribution of the data, we employed the Kolmogorov-Smirnov test. Comparison between the three groups was done using the ANOVA test, and a Bonferroni post hoc test was used. $P$-value $\leq 0.05$ was considered statistically significant.

\section{Ethics statement}

All procedures were in accordance with the ethical standards of the responsible committee on human experimentation in Benha University and with the Helsinki Declaration of 1964, as revised in 2013. Informed written consent was obtained from all participants.

\section{Results}

Our study included 103 eyes of 103 patients (40 males, 63 females) divided in three groups, LASIK group, FSLASIK group, and SMILE group. No intraoperative or postoperative complication was noticed. No statistically significant differences were perceived between the three groups in relation to age, preoperative spherical equivalent (SE), central corneal thickness (CCT), keratometric readings, $\mathrm{CH}, \mathrm{CRF}$, and OSDI score $(P>0.05)$ (Table 1).

Kolmogorov-Smirnov test showed probabilities of $>0.05$ which means that data were normally distributed. A one-way, between-subject ANOVA test revealed significant differences between groups in the mean deviation of central flap and cap thickness from intended thickness at all follow-up
Table I Preoperative selected characteristics

\begin{tabular}{lllll}
\hline Variable & LASIK & $\begin{array}{l}\text { FS-LASIK } \\
\text { group }\end{array}$ & $\begin{array}{l}\text { SMILE } \\
\text { group }\end{array}$ & $P$-value \\
\hline Age (years) & $23.84 \pm 4.75$ & $23.84 \pm 4.75$ & $24.43 \pm 5.91$ & 0.520 \\
Gender (M/F) & $12 / 18$ & $14 / 24$ & $14 / 21$ & - \\
SE (D) & $-7.49 \pm 2.05$ & $-7.14 \pm 1.97$ & $-8.05 \pm 2.06$ & 0.161 \\
CCT $(\mu \mathrm{m})$ & $582.84 \pm 12.25$ & $578.96 \pm 12.06$ & $579.32 \pm 10.65$ & 0.342 \\
Mean K (D) & $43.16 \pm 1.27$ & $43.41 \pm 1.08$ & $43.57 \pm 1.15$ & 0.366 \\
CH $(\mathrm{mmHg})$ & $10.62 \pm 0.53$ & $10.71 \pm 0.47$ & $10.58 \pm 0.39$ & 0.473 \\
CRF $(\mathrm{mmHg})$ & $10.19 \pm 0.12$ & $10.22 \pm 0.10$ & $10.21 \pm 0.09$ & 0.489 \\
OSDI & $11.43 \pm 10.11$ & $11.89 \pm 9.82$ & $11.96 \pm 9.28$ & 0.935 \\
TBUT & $10.11 \pm 1.41$ & $9.87 \pm 1.28$ & $9.93 \pm 1.35$ & $0.57 \mid$ \\
\hline
\end{tabular}

Note: Data are mean \pm SD of 103 eyes of 103 patients.

Abbreviations: LASIK, laser in situ keratomileusis; FS-LASIK, femtosecond laser-LASIK; SMILE, small incision lenticule extraction; SE, spherical equivalent; $\mathrm{CCT}$, central corneal thickness; $\mathrm{K}$, keratometric reading; $\mathrm{CH}$, corneal hysteresis; CRF, corneal resistance factor; OSDI, ocular surface disease index; TBUT, tear breakup time; $\mathrm{M}$, male; $\mathrm{F}$, female.

visits $(P<0.001)$ (Table 2). A Bonferroni post hoc test showed a significant difference in the mean deviation from intended central flap thickness between the LASIK group and the FS-LASIK group $(P<0.001)$ and a significant difference between the LASIK group and the SMILE group $(P<0.001)$. However, no statistically significant difference was noticed between the FS-LASIK group and the SMILE group $(P>0.05)$, the femtolaser machine was more accurate than the microkeratome.

The mean preoperative $\mathrm{CH}$ and $\mathrm{CRF}$ were $10.82 \pm 0.53$ and $10.19 \pm 0.12 \mathrm{mmHg}$, respectively, in the LASIK group, $10.71 \pm 0.47$ and $10.22 \pm 0.20 \mathrm{mmHg}$ respectively in the FS-LASIK group, and $10.58 \pm 0.39$ and $10.21 \pm 0.19 \mathrm{mmHg}$ respectively in the SMILE group. We found no statistically significant differences between groups preoperatively ( $P=0.473$ for $\mathrm{CH}$ and 0.489 for CRF) (Table 1). Both $\mathrm{CH}$ and $\mathrm{CRF}$ decreased significantly postoperatively as compared to preoperative values in the three groups. Both $\mathrm{CH}$ and $\mathrm{CRF}$ were significantly higher in the SMILE group than the other two groups at all postoperative visits $(P<0.05)$, so the extent of changes was less with SMILE (Table 2) (Figures 1 and 2).

The mean preoperative OSDI scores were $11.43 \pm 10.11$ in the LASIK group, $11.89 \pm 9.82$ in the FS-LASIK group, and $11.96 \pm 9.28$ in the SMILE group, and there was no significant difference among the three groups $(P=0.935)$ (Table 1). The mean OSDI scores elevated to $18.51 \pm 14.73$ in the LASIK group, $18.29 \pm 15.24$ in the FS-LASIK group, and $18.12 \pm 13.88$ in the SMILE group at 1 month after surgery and were significantly higher than the preoperative level in the three groups $(P<0.01)$. The mean OSDI scores at 3 months postoperatively were significantly lower in the 
Table 2 Preoperative and postoperative data

\begin{tabular}{|c|c|c|c|}
\hline Variable & $\begin{array}{l}\text { LASIK } \\
\text { group } \\
\text { (30 eyes) }\end{array}$ & $\begin{array}{l}\text { FS-LASIK } \\
\text { group } \\
\text { (38 eyes) } \\
\end{array}$ & $\begin{array}{l}\text { SMILE } \\
\text { group } \\
\text { (35 eyes) }\end{array}$ \\
\hline \multicolumn{4}{|c|}{ Deviation of central flap or cap } \\
\hline \multicolumn{4}{|c|}{ thickness from intended $(\mu \mathrm{m})$} \\
\hline I month postoperative & $23.37 \pm 4.41$ & $5.03 \pm 2.49 *$ & $5.89 \pm 2.22 *$ \\
\hline 3 months postoperative & $23.4 I \pm 4.64$ & $5.13 \pm 3.12^{*}$ & $6.07 \pm 2.88^{*}$ \\
\hline 6 months postoperative & $23.39 \pm 5.43$ & $5.08 \pm 2.39 *$ & $5.96 \pm 2.3 I^{*}$ \\
\hline 12 months postoperative & $23.36 \pm 4.22$ & $5.11 \pm 2.32 *$ & $5.88 \pm 2.29 *$ \\
\hline 24 months postoperative & $23.36 \pm 4.20$ & $5.02 \pm 2.41 *$ & $5.83 \pm 2.31 *$ \\
\hline 36 months postoperative & $23.37 \pm 4.26$ & $5.03 \pm 2.44^{*}$ & $5.82 \pm 2.33^{*}$ \\
\hline \multicolumn{4}{|l|}{$\mathrm{CH}(\mathrm{mmHg})$} \\
\hline Preoperative & $10.82 \pm 0.53$ & $|0.7| \pm 0.47$ & $10.58 \pm 0.39$ \\
\hline I month postoperative & $7.5 I \pm 0.73^{\ddagger}$ & $7.66 \pm 0.64^{\ddagger}$ & $8.43 \pm 0.32 \neq *, * *$ \\
\hline 3 months postoperative & $7.50 \pm 0.60^{\ddagger}$ & $7.63 \pm 0.58^{\ddagger}$ & $8.4 I \pm 0.4 I^{\ddagger}, * * * *$ \\
\hline 6 months postoperative & $7.47 \pm 0.54^{\ddagger}$ & $7.58 \pm 0.60 \ddagger$ & $8.40 \pm 0.37^{\ddagger}, *, * *$ \\
\hline 12 months postoperative & $7.45 \pm 0.65^{\ddagger}$ & $7.56 \pm 0.44^{\ddagger}$ & $8.37 \pm 0.40^{\ddagger} \neq, * *$ \\
\hline 24 months postoperative & $7.55 \pm 0.63^{\ddagger}$ & $7.59 \pm 0.5 I^{\ddagger}$ & $8.44 \pm 0.47^{\ddagger} *, * * *$ \\
\hline 36 months postoperative & $7.58 \pm 0.7 I^{\ddagger}$ & $7.60 \pm 0.61^{\ddagger}$ & $8.5 \mathrm{I} \pm 0.5 \mathrm{I} \neq *, * * *$ \\
\hline \multicolumn{4}{|l|}{ CRF $(\mathrm{mmHg})$} \\
\hline Preoperative & $10.19 \pm 0.22$ & $10.22 \pm 0.20$ & $10.21 \pm 0.19$ \\
\hline I month postoperative & $7.15 \pm 0.50^{\ddagger}$ & $7.24 \pm 0.73^{\ddagger}$ & $8.35 \pm 0.41 \neq, *, * *$ \\
\hline 3 months postoperative & $7.13 \pm 0.44^{\ddagger}$ & $7.22 \pm 0.8 I^{\ddagger}$ & $8.32 \pm 0.56 \neq *, * *$ \\
\hline 6 months postoperative & $7.12 \pm 0.76^{\ddagger}$ & $7.21 \pm 0.65^{\ddagger}$ & $8.30 \pm 0.48 * *, * *$ \\
\hline 12 months postoperative & $7.11 \pm 0.57^{\ddagger}$ & $7.18 \pm 0.59 \ddagger$ & $8.29 \pm 0.32 \ddagger *, * *$ \\
\hline 24 months postoperative & $7.18 \pm 0.54^{\ddagger}$ & $7.26 \pm 0.7 I^{\ddagger}$ & $8.35 \pm 0.42^{\ddagger *}, * *$ \\
\hline 36 months postoperative & $7.17 \pm 0.68^{\ddagger}$ & $7.25 \pm 0.69 \ddagger$ & $8.38 \pm 0.59 \neq *, * * *$ \\
\hline \multicolumn{4}{|l|}{ OSDI } \\
\hline Preoperative & $11.43 \pm 10.11$ & $11.89 \pm 9.82$ & $11.96 \pm 9.28$ \\
\hline I month postoperative & $|8.5| \pm \mid 4.73^{\ddagger}$ & $18.29 \pm 15.24 \ddagger$ & $18.12 \pm 13.88^{\ddagger}$ \\
\hline 3 months postoperative & $16.42 \pm 12.09 \ddagger$ & $15.95 \pm|| .83^{\ddagger}$ & $12.03 \pm 9.87^{* * * *}$ \\
\hline 6 months postoperative & $12.27 \pm 10.85$ & $12.05 \pm 11.43$ & $11.51 \pm 10.15$ \\
\hline 12 months postoperative & $\mid 1.71 \pm 10.43$ & $11.86 \pm 10.92$ & $11.13 \pm 10.02$ \\
\hline 24 months postoperative & $11.53 \pm 9.54$ & $11.88 \pm 10.06$ & $11.27 \pm 9.06$ \\
\hline 36 months postoperative & $11.49 \pm 9.97$ & $11.85 \pm 10.02$ & $11.18 \pm 8.94$ \\
\hline \multicolumn{4}{|l|}{ TBUT } \\
\hline Preoperative & $|0.1| \pm|.4|$ & $9.87 \pm 1.28$ & $9.93 \pm 1.35$ \\
\hline I month postoperative & $6.21 \pm 1.27^{\ddagger}$ & $6.32 \pm 1.39 \ddagger$ & $6.68 \pm 1.43^{\ddagger}$ \\
\hline 3 months postoperative & $7.38 \pm 1.19 \neq$ & $7.56 \pm 1.43^{\ddagger}$ & $7.92 \pm 1.52^{\ddagger}$ \\
\hline 6 months postoperative & $8.03 \pm 1.46^{\ddagger}$ & $8.09 \pm 1.62^{\ddagger}$ & $9.61 \pm 1.51 * * *$ \\
\hline 12 months postoperative & $9.27 \pm 1.25$ & $9.31 \pm 1.38$ & $9.81 \pm 1.34$ \\
\hline 24 months postoperative & $9.43 \pm 1.60$ & $9.57 \pm 1.54$ & $9.88 \pm 1.37$ \\
\hline 36 months postoperative & $9.72 \pm 1.39$ & $9.81 \pm 1.61$ & $9.91 \pm 1.23$ \\
\hline
\end{tabular}

Notes: Data are mean \pm SD. $\neq$ Statistically significant difference from the preoperative value, *statistically significant difference from the LASIK group, **statistically significant difference from the FS-LASIK group.

Abbreviations: LASIK, laser in situ keratomileusis; FS-LASIK, femtosecond laser-LASIK; SMILE, small incision lenticule extraction; CH, corneal hysteresis; CRF, corneal resistance factor; OSDI, ocular surface disease index; TBUT, tear breakup time.

SMILE group $(12.03 \pm 9.87)$ when compared to the other

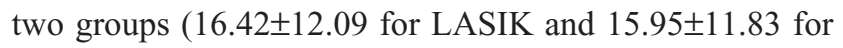
FS-LASIK $[P>0.05])$, but there were no significant differences between the three groups afterward, so OSDI scores returned to preoperative values earlier in the SMILE group (Figure 3) (Table 2).

The mean preoperative TBUT was $10.11 \pm 1.41 \mathrm{~s}$ in the LASIK group, $9.87 \pm 1.28 \mathrm{~s}$ in the FS-LASIK group, and $9.93 \pm 1.35 \mathrm{~s}$ in the SMILE group, and there was no significant difference among the three groups $(P=0.571)$ (Table 1$)$. The mean TBUT decreased to $6.21 \pm 1.27 \mathrm{~s}$ in the LASIK group, $6.32 \pm 1.39 \mathrm{~s}$ in the FS-LASIK group, and $6.68 \pm 1.43 \mathrm{~s}$ in the SMILE group at 1 month after surgery, and were significantly lower than the preoperative level in the three groups $(P<0.01)$. The mean TBUT 6 months postoperatively was significantly higher in the SMILE group $(9.61 \pm 1.51 \mathrm{~s})$ when compared to the other two groups $(8.03 \pm 1.46 \mathrm{~s}$ for LASIK and $8.09 \pm 1.62 \mathrm{~s}$ for FS-LASIK $)(P>0.05)$, so TBUT 




Figure I Preoperative (pre-op) and postoperative (post-op) corneal hysteresis $(\mathrm{CH})$ changes in the three groups.

Abbreviations: LASIK, laser in situ keratomileusis; FS-LASIK, femtosecond laser-LASIK; SMILE, small incision lenticule extraction.

returned to preoperative values earlier in the SMILE group (Figure 4) (Table 2).

\section{Discussion}

During the LASIK procedure, it is crucial to have a uniform flap with a narrow deviation from the intended thickness to leave an appropriate residual stromal thickness after ablation. ${ }^{16,17}$ The SMILE procedure is the latest advance in femtosecond laser assisted corneal refractive surgeries, during which the anterior lamellar cut is like the flap cut in LASIK and FemtoLASIK. Previous studies were carried out to assess and compare the FemtoLASIK and SMILE procedures. ${ }^{2,11,13}$ In this study, we evaluated the femtosecond laser for the creation of the flaps for LASIK and the caps for SMILE, so we studied the thickness of the flaps and caps, $\mathrm{CH}, \mathrm{CRF}$, OSDI, and TBUT.
Our results of the mean deviation from intended flap and cap thickness showed statistically significant differences between the LASIK group and the other two groups $(P<0.001)$. These results are in line with those of Xia et al, ${ }^{11}$ who compared the flaps created by the microkeratomes to the flaps created by femtosecond laser, and found that the femtosecond laser has an advantage in the flap thickness predictability. Also, in Zhang et al's study, ${ }^{17}$ AS-OCT showed that the flaps formed by the WaveLight femtosecond laser were more precise, reproducible, and uniform than those formed by the Moria microkeratome. On the other hand, there were no statistically significant differences between the FS-LASIK group and the SMILE group in relation to the mean deviation from intended flap and cap thickness $(P=0.1241)$. Consistently, this was the case in Ozgurhan et al's ${ }^{13}$ study, which compared the cap thickness of SMILE

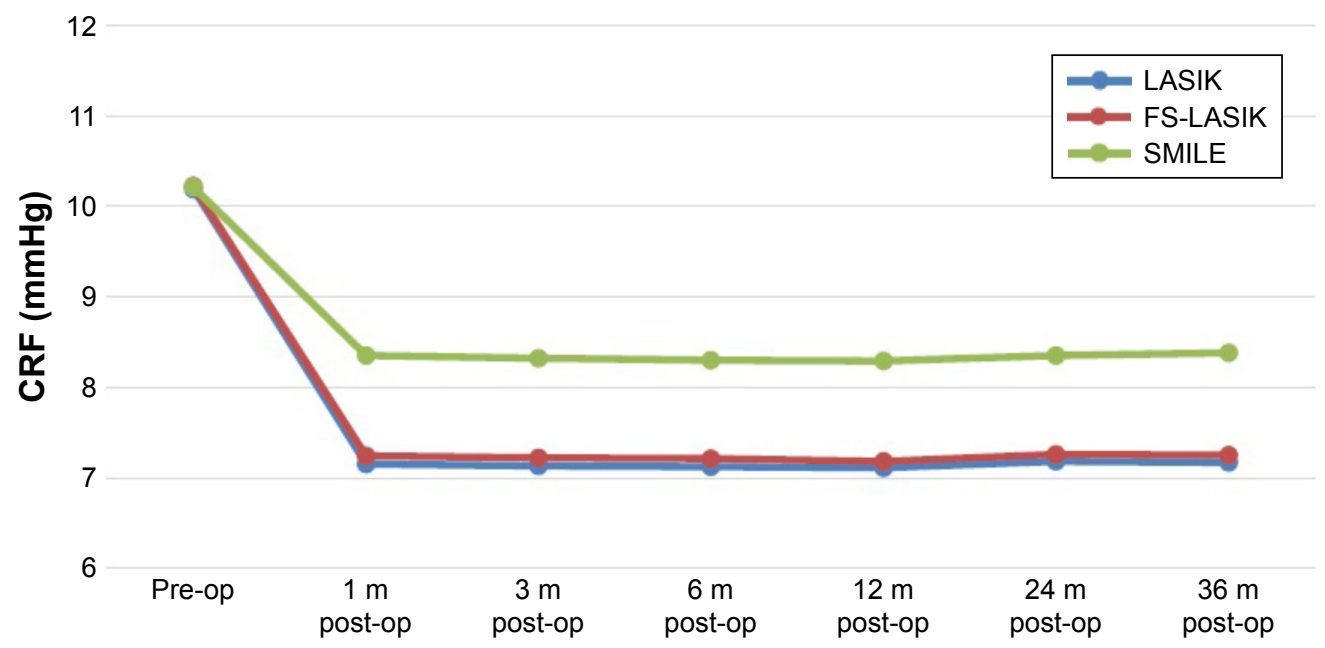

Figure 2 Preoperative (pre-op) and postoperative (post-op) corneal resistance factor (CRF) changes in the three groups.

Abbreviations: LASIK, laser in situ keratomileusis; FS-LASIK, femtosecond laser-LASIK; SMILE, small incision lenticule extraction. 


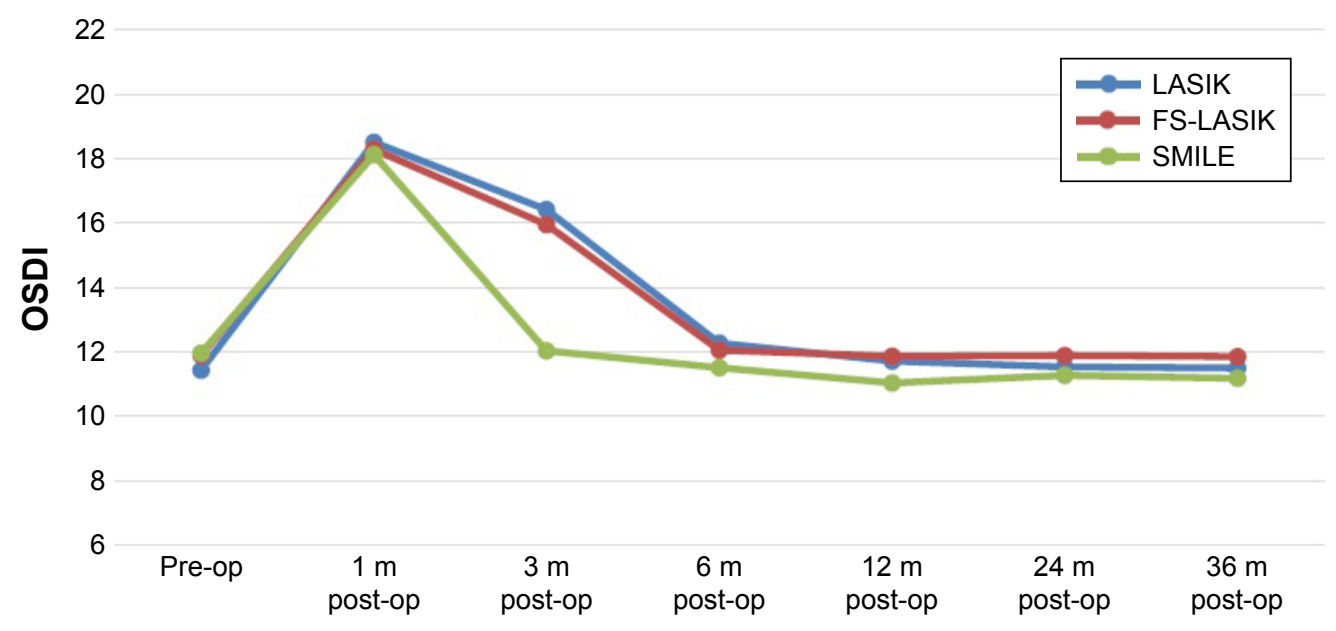

Figure 3 Preoperative (pre-op) and postoperative (post-op) ocular surface disease index (OSDI) changes in the three groups.

Abbreviations: LASIK, laser in situ keratomileusis; FS-LASIK, femtosecond laser-LASIK; SMILE, small incision lenticule extraction.

and flap thickness of FemtoLASIK and concluded that the cap thickness in SMILE surgery does not differ from flaps formed using the same femtosecond laser platform.

$\mathrm{CH}$ and $\mathrm{CRF}$ are two of the corneal biomechanical characteristics which refer to the corneal viscoelastic properties. ${ }^{18}$ It is very important to note that $\mathrm{CH}$ and $\mathrm{CRF}$ do not express stiffness or the stress-strain behavior of corneal tissue. ${ }^{19} \mathrm{As} \mathrm{CH}$ and CRF are related to age, and previous studies settled that the $\mathrm{CH}$ is affected by the $\mathrm{CCT},{ }^{20}$ the patients in this study were selected to be of nearly the same age and have similar CCT. Both $\mathrm{CH}$ and $\mathrm{CRF}$ declined significantly postoperatively as compared to preoperative values in the three groups. Both $\mathrm{CH}$ and CRF presented statistically significant differences between the SMILE group and the other two groups at all postoperative visits during the 3-year follow-up period. We think that there are two possible explanations for different behavior of $\mathrm{CH}$ and CRF in the SMILE group; the anterior stroma and Bowman's layer are not interrupted, and the interface healing may differ as there was no ablation. These results are in line with that of Wu et al, ${ }^{21}$ who studied $\mathrm{CH}$ and CRF after both the SMILE and FemtoLASIK procedures. They reported that both $\mathrm{CH}$ and CRF were significantly diminished after both procedures, however the deviations in the corneal biomechanical parameters were less after SMILE than after FemtoLASIK. Wang et $\mathrm{a}^{22}$ compared $\mathrm{CH}$ and CRF before and after SMILE and FemtoLASIK in different degrees of myopia. They found that there was no significant difference between the two groups in myopia less than -6 D. However, in eyes with myopia more than $-6 \mathrm{D}$, the $\mathrm{CH}$ and $\mathrm{CRF}$ decreased significantly more in LASIK than in SMILE cases. In our study, we found significant differences between the three groups, and this may be attributed to the degree of myopia as the mean SE was -7.56 D. Kamiya et $\mathrm{a}^{23}$ studied some of the biomechanical characteristics of the cornea after SMILE procedure, and they found

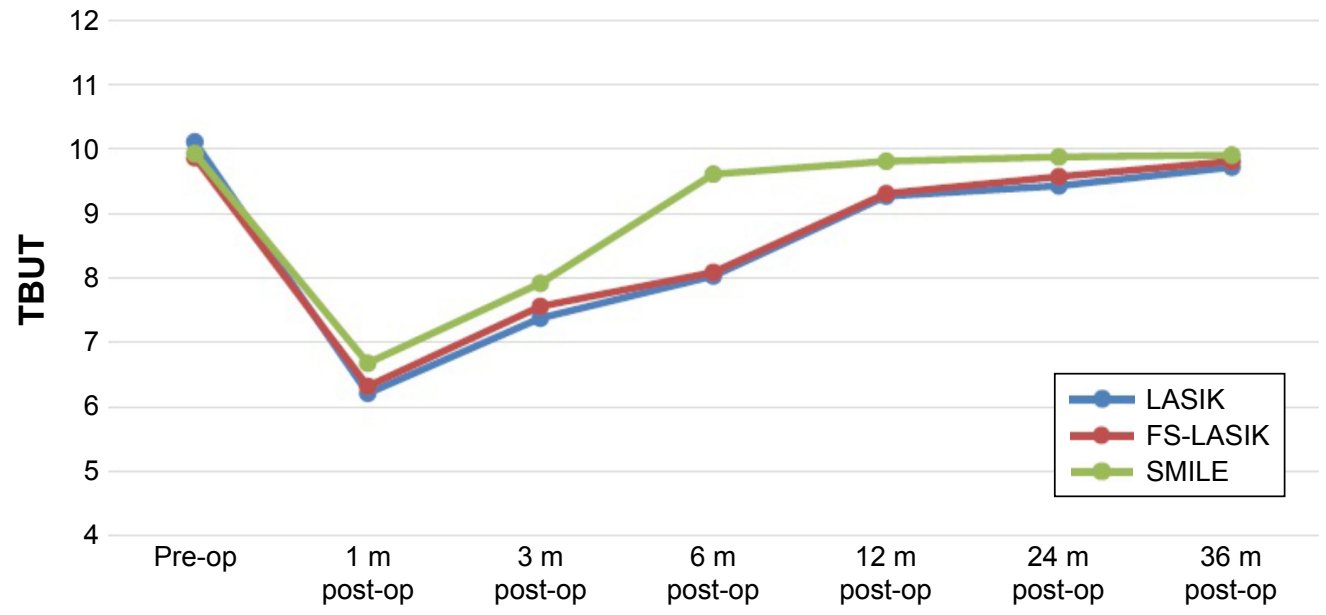

Figure 4 Preoperative (pre-op) and postoperative (post-op) tear breakup time (TBUT) changes in the three groups. 
that the highest changes in the corneal biomechanics occurred during the first week postoperatively, and they became stable after that. The results of our study showed stability of both $\mathrm{CH}$ and $\mathrm{CRF}$ throughout the postoperative follow-up period.

Dry eye is prevalent among patients who undergo corneal refractive surgeries, the incidence of dry eye varies among patients. We used the TBUT test as an objective indicator and the OSDI score as a subjective indicator for dryness. We found a statistically significant increase in OSDI and decrease in TBUT at 1 month postoperatively when compared to the preoperative levels in the three groups. The mean OSDI scores returned to preoperative level at 3 months after surgery for the SMILE group $(12.03 \pm 10.07)$, while it took 6 months to return to preoperative level in the LASIK group and the FemtoLASIK group (Figure 3). These results agree with those of Wang et al, who compared dry eye disease following SMILE versus FS-LASIK using TBUT and Salisbury Eye Evaluation Questionnaire (SEEQ). They found that TBUT was higher after SMILE than FS-LASIK at 3, 6, and 12 months post-operatively $(P<0.001)$ and SEEQ scores were less after SMILE than FSLASIK at 1,3 , and 6 months post-operatively $(P<0.001){ }^{24}$

\section{Conclusion}

Our results showed that femtosecond laser (Carl Zeiss Meditec VisuMax femtosecond laser system) is more accurate and more predictable than mechanical microkeratomes. $\mathrm{CH}$ and $\mathrm{CRF}$ changes are less after the SMILE procedure. The three procedures led to significant dryness, but for a shorter duration in SMILE.

\section{Acknowledgment}

Part of this study was presented by Dr Mohamed Nagy Elmohamady as a poster in the ESCRS conference, Copenhagen, Denmark, 2016.

\section{Disclosure}

The authors report no conflicts of interest in this work.

\section{References}

1. Liu Q, Zhou YH, Zhang J, et al. Comparison of corneal flaps created by Wavelight FS200 and Intralase FS60 femtosecond lasers. Int $J$ Ophthalmol. 2016;9(7):1006-1010.

2. Pietilä J. Flap Creation in Laser-Assisted in Situ Keratomileusis: From Microkeratome to Femtosecond Laser. Tampere: Tampere University Press; 2012.

3. Reggiani-Mello G, Krueger RR. Comparison of commercially available femtosecond lasers in refractive surgery. Expert Rev Ophthalmol. 2011;6(1):55-65.

4. Ye M, Liu C, Liao R, et al. SMILE and Wavefront-guided LASIK out-compete other refractive surgeries in ameliorating the induction of high-order aberrations in anterior corneal surface. J Ophthalmol. 2016; 2016:8702162.
5. Chansue E, Tanehsakdi M, Swasdibutra S, McAlinden C. Efficacy, predictability and safety of small incision lenticule extraction (SMILE). Eye Vis (Lond). 2015;2:14.

6. Chen MC, Lee N, Bourla N, Hamilton DR. Corneal biomechanical measurements before and after laser in situ keratomileusis. J Cataract Refract Surg. 2008;34(11):1886-1891.

7. Lau W, Pye D. A clinical description of Ocular Response Analyzer measurements. Invest Ophthalmol Vis Sci. 2011;52(6):2911-2916.

8. Uzbek AK, Kamburoğlu G, Mahmoud AM, Roberts CJ. Change in biomechanical parameters after flap creation using the Intralase femtosecond laser and subsequent excimer laser ablation. Curr Eye Res. 2011;36(7):614-619.

9. Salomao MQ, Ambrosio R Jr, Wilson SE. Dry eye associated with laser in situ keratomileusis: mechanical microkeratome versus femtosecond laser. J Cataract Refract Surg. 2009;35(10):1756-1760.

10. Ambrosio R Jr, Tervo T, Wilson SE. LASIK-associated dry eye and neurotrophic epitheliopathy: pathophysiology and strategies for prevention and treatment. J Refract Surg. 2008;24(4):396-407.

11. Xia LK, Yu J, Chai GR, Wang D, Li Y. Comparison of the femtosecond laser and mechanical microkeratome for flap cutting in LASIK. Int $J$ Ophthalmol. 2015;8(4):784-790.

12. Sekundo W, Kunert K, Russman C, et al. First efficacy and safety study of femtosecond lenticule extraction for the correction of myopia: six-month results. J Cataract Refract Surg. 2008;34(9):1513-1520.

13. Ozgurhan EB, Agca A, Bozkurt E, et al. Accuracy and precision of cap thickness in small incision lenticule extraction. Clin Ophthalmol. 2013; 7:923-926.

14. Li M, Zhao J, Shen Y, et al. Comparison of dry eye and corneal sensitivity between small incision lenticule extraction and femtosecond LASIK for myopia. PLoS One. 2013;8(10):e77797.

15. Sefat SM, Wiltfang R, Bechmann M, et al. Evaluation of changes in human corneas after femtosecond laser-assisted LASIK and smallincision lenticule extraction (SMILE) using non-contact tonometry and ultra-high-speed camera (Corvis ST). Curr Eye Res. 2016;41(7): 917-922.

16. Binder PS, Trattler WB. Evaluation of a risk factor scoring system for corneal ectasia after LASIK in eyes with normal topography. $J$ Refract Surg. 2010;26(4):241-250.

17. Zhang Y, Chen YG, Xia YJ. Comparison of corneal flap morphology using AS-OCT in LASIK with the WaveLight FS200 femtosecond laser versus a mechanical microkeratome. J Refract Surg. 2013;29(5): 320-324.

18. Luce DA. Determining in vivo biomechanical properties of the cornea with an ocular response analyzer. J Cataract Refract Surg. 2005;31(1): $156-162$.

19. Luz A, Faria-Correia F, Salomão MQ, Lopes BT, Ambrósio R. Corneal biomechanics: Where are we? J Curr Ophthalmol. 2016;28(3): 97-98.

20. Kotecha A, Elsheikh A, Roberts CR, Zhu H, Garway-Heath DF. Corneal thickness- and age-related biomechanical properties of the cornea measured with the ocular response analyzer. Invest Ophthalmol Vis Sci. 2006;47(12):5337-5347.

21. Wu D, Wang Y, Zhang L, Wei S, Tang X. Corneal biomechanical effects: small-incision lenticule extraction versus femtosecond laserassisted laser in situ keratomileusis. J Cataract Refract Surg. 2014;40(6): 954-962.

22. Wang D, Liu M, Chen Y, et al. Differences in the corneal biomechanical changes after SMILE and LASIK. J Refract Surg. 2014;30(10):702-707.

23. Kamiya K, Shimizu K, Igarashi A, Kobashi H, Sato N, Ishii R. Intraindividual comparison of changes in corneal biomechanical parameters after femtosecond lenticule extraction and small-incision lenticule extraction. J Cataract Refract Surg. 2014;40(6):963-970.

24. Wang B, Naidu RK, Chu R, et al. Dry eye disease following refractive surgery: a 12-month follow-up of SMILE versus FS-LASIK in high myopia. J Ophthalmol. 2015;2015:132417. 


\section{Publish your work in this journal}

Clinical Ophthalmology is an international, peer-reviewed journal covering all subspecialties within ophthalmology. Key topics include: Optometry; Visual science; Pharmacology and drug therapy in eye diseases; Basic Sciences; Primary and Secondary eye care; Patient Safety and Quality of Care Improvements. This journal is indexed on

Submit your manuscript here: http://www.dovepress.com/clinical-ophthalmology-journal
PubMed Central and CAS, and is the official journal of The Society of Clinical Ophthalmology (SCO). The manuscript management system is completely online and includes a very quick and fair peer-review system, which is all easy to use. Visit http://www.dovepress.com/ testimonials.php to read real quotes from published authors. 